\title{
Trafik Kazası ile Gelen Pediatrik Hastalarda, Kaza Oluş Şekilleri ile Travma Skorlarının Değerlendirilmesi
}

\author{
Dilek ATÍK ${ }^{1}$, Başar CANDER ${ }^{2}$, Cesareddin DİKMETAŞ $^{2}$, Bensu BULUT $^{2}$, \\ Eren SERT ${ }^{2}$, Hilmi KAYA ${ }^{2}$, Ramazan GUVEN ${ }^{2}$, Atıf BAYRAMOĞLU ${ }^{3}$ \\ 1 Yozgat Bozok Üniversitesi Tip Fakültesi, Acil Tıp Anabilim Dalı, Yozgat. \\ 2 Sağlık Bilimleri Üniversitesi, Kanuni Sultan Süleyman Eğitim ve Araştırma Hastanesi Acil Tıp Kliniği, \\ İstanbul. \\ 3 Gülhane Eğitim ve Araştırma Hastanesi, Acil Tıp Kliniği, Ankara.
}

\section{ÖZET}

Çocuk acil servisinde travmanın en yaygın nedeni trafik kazalarıdır. Bu çalışmada trafik kazası geçiren çocuk travma hastalarında trafik kazası tipini ve anatomik travma skorlarını değerlendirmeyi amaçladık. Bu çalışma hastane otomasyon sistemi, adli kayıtlar ve pediatrik hasta dosyaları incelenerek retrospektif olarak yapıldı. Tam kayıtları olan 443 hasta çalışmaya dahil edildi. Çalı̧̧maya alınan hastaların\% 64.1'i erkek,\% 35.2'si kadın ve ortalama yaş 8.9 idi. Trafik kazası türlerine göre\% 60.5 Araç dışı trafik kazası, \% 32.3 Araç içi trafik kazası ve $\% 7.2$ hasta motosiklet kazalarıydı. AIS skorunun ortalaması 1.91 1.28, ISS skorunun ortalamas1 $3.32 \pm 3.76$ idi. Trafik Kazası Tipine göre AIS ve ISS travma skorları arasında istatistiksel olarak anlamlı bir fark bulunmadı. AIS ve ISS travma skorları hastaneye yatı̧ ve taburculuk açısından ROC analizi ile değerlendirildiğinde, AIS skoru kesme noktasının 4 üzerindeydi ve kesme noktası 7'nin üzerinde olan ISS skoru hastaneye yatış açısından değerlendirilen kesme noktalarıdır. Sonuç olarak AIS ve ISS skorları; Travma merkezlerinin derecesine göre, transfer planlamasında zaman kaybetmemek için kullanılabilecek puanlar olduğunu düşünüyoruz.

Anahtar Kelimeler: Travma skorları. Trafik kazası. Pediatrik hasta. AIS skoru. ISS skoru.

Evaluation of Accident Types and Trauma Scores in Pediatric Patients Admitted with Traffic Accident

\begin{abstract}
The most common cause of trauma in the pediatric emergency department is traffic accidents. In this study, we aimed to evaluate the type of traffic accident and anatomical trauma scores in pediatric trauma patients admitted with traffic accidents. This study was performed retrospectively by examining hospital automation system, forensic records and patient files of the pediatric. 443 patients with complete records were included in the study. Of the patients included in the study, $\% 64.1$ were male, $35.2 \%$ were female and the mean age was 8.9. According to the traffic accident types patients involved in 60.5\% NVTA, 32.3\% RTA and 7.2\% were motorcycle accidents. The mean AIS score was $1.91 \pm 1.28$, and the ISS score was $3.32 \pm 3.76$. No statistically significant difference was found between trauma scores AIS and ISS with regards to Traffic Accident Type. When the AIS and ISS trauma scores were evaluated by ROC analysis in terms of hospitalization and discharge, the AIS score was above cut-off point 4, and ISS score having cut-off point above 7 are the cut off points evaluated with regards to hospitalization. As a result, AIS and ISS scores; According to the degree of trauma centers, we think there are points that can be used in order not to waste time in transfer planning.
\end{abstract}

Key Words: Trauma scores. Traffic accident. Pediatric patient. AIS score. ISS score.

Karayolu Trafiği; canlıların ve motorlu taşıtların karayolu üzerindeki hal ve hareketleridir. Trafik kazası ise karayolunda hareket halinde olan bir veya birden fazla aracın karıştığı yaralamalı, ölümlü veya maddi zararla

Geliş Tarihi: 05.Aralık.2019

Kabul Tarihi: 01.Nisan.2020

Dr. Dilek ATiK

Yozgat Bozok Üniversitesi Tıp Fakültesi,

Acil Tıp Anabilim Dalı, Yozgat.

Tel.: 05059445091

E-posta: dr.dilekgok82@hotmail.com sonuçlanmış olaylardır ${ }^{1}$. 2018 TÜIKK verilerine göre 307.071 kişi karayolu trafik kazasına bağlı olarak yaralanmış ve 6675 kişi karayolu trafik kazasından dolayı hayatın kaybetmiştir². Karayollarındaki taşıt sayısı artıkça yaralanma ve ölüm oranları gün geçtikçe artmaktadır. 2002'den bu yana yaralı sayısı yaklaşı olarak 2 kat kadar artmıştır' ${ }^{2}$.Gelişmekte olan ülkelerde çocukluk çağı ölüm nedenleri arasında travma, ilk sırada yer almaktadır ${ }^{3,4}$. Çocukluk çağında, anatomik yapıları yetişkinlerden farklılıklar arz eder ${ }^{5,6}$. Bundan dolayı travmada meydana gelen organ yaralanmalarında; travmanın oluş şekli ve mekanizmasına göre 
değișmekle birlikte yetișkinlerden farklıdır. Çocuk hastalarda travma nedenli acil servis başvurularında trafik kazaları ilk sırada yer almaktadır ${ }^{7}$. Travma hastalarında; hastane öncesi ve hastane içi ortak dil kullanım adına birçok skorlama sistemleri geliştirilmiştir. Skorlama sistemleri; tedavi ve sonuçlar arasındaki ilişki hakkında bilgi sahibi olmamızı sağlamaktadır ${ }^{8}$. Yaralanmaların ciddiyetini belirlemek adına 1960 yıllından beri birçok skor sistemi geliştirilmeye çal1şılmıştır.1976'de tanımlanan travma ölçeklerinden olan AIS (Kısaltılmış yaralanma ölçeği) 3 defa revizyon uygulanmıştır ${ }^{9}$. AIS Yaralanan bölgenin genişliğine göre vücut alanları sınıflandırılır. ISS(Yaralanma ciddiyet skoru) ise travma geçiren popülasyonda Anatomik yaralanma şiddeti göstergelerinde "altın standart"tır ${ }^{10,11}$. Hastaların başvuru anından itibaren hasta takibinde kullanılan fizyolojik puanlama sistemlerinden birisi olan GKS (Glaskow koma skoru); bilinç düzeyini ifade edebilen, koma derecesinin güvenilir bir şekilde değerlendirilmesinde sık kullanılan, basit, objektif bir puanlama sistemidir ${ }^{12}$.Günümüzde ilk yardım hizmetleri gelişen teknoloji ve imkanlarla her geçen gün artmaktadır. Hızlı ve uygun şekilde gerçekleştirilecek ilk müdahale ile ölümlerin \%30'unun önlenebileceği tahmin edilmektedir ${ }^{13}$.Çalışmamızda trafik kazası ile gelen çocuk travma hastalarında trafik kazası oluş biçimi ile anatomik tavma skorlarını değerlendirilmeyi amaçladık.

\section{Gereç ve Yöntem}

$\mathrm{Bu}$ çalışma İstanbul Sağlık Bilimleri Üniversitesi Kanuni Sultan Süleyman Eğitim ve Araştırma Hastanesi Acil Tıp Kliniğine 01.01.2018-31.12.2018 tarihleri arasında Trafik kazası nedeniyle gelen pediatrik olguları retrospektif olarak hastane otomasyon sistemi, adli kayıtlar ve hasta dosyaları incelenerek yapıldı. Çalışmaya 0-17 yaş arası hastalar dahil edildi. Çalışmanın yapılabilmesi için lokal etik kuruldan 2017KAEK-189 karar numarası ile onay alındı. Kayıtları tam olan 443 hasta çalışmaya dahil edildi. Hastaların verilerinden yaş, klinik sonuç, trafik kaza oluş biçimi, GKS her biri kendi içinde gruplara ayrıldı. Hastaların yaralanan vücut bölgeleri her hasta için dosyalarından kayıt edildi. Trafik kaza oluş biçimleri; ADTK (Araç dışı trafik kazası), AİTK (Araç içi trafik kazası), MK(Motosiklet kazası) 3 gruba ayrıldı. Yaş Faktörü; 0-2 ,3-6, 7-12 ve 13-18 olarak 4 gruba ayrıldı.Klinik nihai sonuçları; sağlıklı şekilde taburcu, servise yatış, yoğun bakıma yatış ve eksitus şeklinde 4 gruba ayrıldı. Glaskow Koma skalası; GKS 15 Grup 1, GKS 14-10 Grup 2, GKS 9-6 Grup 3, GKS <5 Grup 4 olarak gruplara ayrildı.

\section{Kullanılan ölçekler:}

AIS (Kısaltıımış yaralanma skalası):AIS-90, 2000 'den fazla yaralanma tanımlayıcısını dokuz vücut bölgesinde (baş, yüz, boyun, göğüs, karın, omurga, üst ekstremiteler, alt ekstremiteler ve pelvis) sınıflandırır. Her yaralanmaya sıradan bir ölçekte 1 (küçük yaralanma) ile 6 (maksimum yaralanma, muhtemelen ölümcül) arasında değişen bir AIS puanı belirlenir. Bu amaç ile birçok anatomik bölgede tanımlanan $75^{\text {'e }}$ yakın yaralanma sınıflandırılmıştır.

ISS (Yaralanma ciddiyet skoru): ISS 1 ila 75 arasında değişen bir anatomik tabanlı sıra ölçeğidir. ISS'yi hesaplamak için dokuz AIS vücut bölgesi altıya ayrılmıştır. ISS daha sonra en ağır yaralanan üç vücut bölgesi için en yüksek AIS puanlarının karelerinin toplamı olarak hesaplanır ${ }^{14,15}$.

GKS (Glaskow koma skalası): Glaskow koma skalas1 motor tepkisi, göz tepkisi ve sözlü tepki diye 3 parametreden oluşur. Motor tepki 1 -6 arasında, göz tepki 1-4 arasında ve sözlü tepki 1-5 arası puanlanır.3 tepkini aldığ 1 toplam puan GKS gösterir.

\section{İstatistik analiz:}

Tüm istatistiksel veriler Windows için SPSS 20.0 versiyonu programı ile yapıldı. İstatistik Analizler olarak tüm değişkenlere normal dağılıma uygunluk testi, KolmogorovSmirnov test yapılarak parametrik test kriterlerine uyum değerlendirildi. Klinik araştırma kapsamında gerçekleştirilen çalışma ile elde edilen veriler istatistiksel olarak nonparametrik niteliktedir. $\mathrm{Bu}$ nedenle de ilişki kurulan değişkenlerin kategorik (nominal ya da ordinal), nümerik bağımsız grup olma durumuna göre de istatistiksel değerlendirmelerde Kruskal-Wallis $\mathrm{H}$ testi ve Mann- Whitney $\mathrm{U}$ testi kullanılmıştır. Nonparamerik nitel veriler için Kikare uygunluk ve bağımsızlık testi uygulandı. Ki kare bağımsızlık testi karşılamadığında FisherExact's testi uygulandı. Hastaların demografik incelemesinde betimleyici istatistlik kullanıld. $\mathrm{p}<0.05$ istatistiksel olarak anlamlı kabul edildi.AIS ve ISS skorlarının etkinliği ROC eğrisi (Receiver-Operating CharacteristicsCurve) ile değerlendirildi.

\section{Bulgular}

Belirlenen tarihlerde hastane sistemine 470 hasta kaydına ulaşıldı. 27 hastanın veri eksikliği nedeniyle toplam 443 hasta çalışmaya dahil edildi. Çalışmaya toplamda 443 hasta alındı. Çalışmaya alınan bu hastaların \%64.1 $(\mathrm{n}=286)$ erkek, \%35.2 $(\mathrm{n}=157)$ kadın, yaş ortalaması 8.9 (min,max) $(0,17)$ idi.

Tablo I'de verildiği üzere Trafik kazalarının mevsimlere göre değerlendirildiğinde; \%32.5 ( $\mathrm{n}=144)$ yaz mevsimi,\% $27.1 \quad(n=120)$ ilkbahar, \%23.9 $(n=106)$ sonbahar, \% $16.5(n=73)$ kış mevsiminde trafik kazası 
geçirmiştir (Tablo I) (Şekil 1). Trafik kazalarının mevsimlere göre bu farlılığ istatistiksel olarak değerlendirildiğinde; ki-kare bağımsızlık testi ile aralarında istatistiksel olarak anlamlı fark bulundu $\left(x^{2}: 23.826\right.$, $\mathrm{p}<0.05)$.

Tablo I. Hastaların Demografik Özellikleri

\begin{tabular}{|c|c|c|c|c|c|c|}
\hline $\begin{array}{c}\text { Demografik } \\
\text { Özellikler - } \\
\text { Değişkenler (IVs) }\end{array}$ & Özellikadı & Kısaltma & Sayı & $\begin{array}{l}\text { Yüzde } \\
\text { (\%) }\end{array}$ & $\begin{array}{l}\text { Sdt. } \\
\text { Spm }\end{array}$ & Skala \\
\hline \multirow[t]{3}{*}{ Cinsiyet } & Kadın (0) & KDN & 157 & 35.5 & & \\
\hline & Erkek(1) & ERK & 286 & 64.5 & & \\
\hline & TOTAL & & 443 & 100 & 0.478 & $0-1$ \\
\hline Yaş & TOTAL & Yaş & 443 & & 4.55 & $0-17$ \\
\hline \multirow[t]{4}{*}{$\begin{array}{c}\text { Trafik kazası oluş } \\
\text { şekli }\end{array}$} & $\begin{array}{c}\text { Araç dışı trafik } \\
\text { kazası (1) }\end{array}$ & ADTK & 268 & 60.5 & & \\
\hline & $\begin{array}{l}\text { Araç içi trafik } \\
\text { kazası (2) }\end{array}$ & AITK & 143 & 32.3 & & \\
\hline & $\begin{array}{c}\text { Motorsiklet kazası } \\
\text { (3) }\end{array}$ & MK & 32 & 7.2 & & \\
\hline & TOTAL & & 443 & 100 & & \\
\hline \multirow[t]{5}{*}{$\begin{array}{l}\text { Mevsimine Göre } \\
\text { Trafik Kazası }\end{array}$} & Yaz & $Y Z$ & 144 & 32.5 & & \\
\hline & Illkbahar & İLK & 120 & 27.1 & & \\
\hline & Sonbahar & $\mathrm{SBH}$ & 106 & 23.9 & & \\
\hline & Kış & $\mathrm{KŞ}$ & 73 & 16.5 & & \\
\hline & TOTAL & & 443 & 100 & & \\
\hline \multirow[t]{2}{*}{$\begin{array}{c}\text { Travma skor } \\
\text { ortalaması }\end{array}$} & $\begin{array}{c}\text { Kısaltıımış } \\
\text { yaralanma ölçeği }\end{array}$ & AIS & 1.91 & & 1.28 & $1-10$ \\
\hline & $\begin{array}{c}\text { Yaralanma } \\
\text { ciddiyet ölçeği }\end{array}$ & ISS & 3.32 & & 3.76 & $1-34$ \\
\hline \multirow[t]{5}{*}{$\begin{array}{c}\text { Glaskow Koma } \\
\text { Ölçeği }\end{array}$} & $15(1)$ & GKS1 & 442 & 99.8 & & \\
\hline & $14-10(2)$ & GKS2 & 0 & 0 & & \\
\hline & $9-6(3)$ & GKS3 & 0 & 0 & & \\
\hline & $<5(4)$ & GKS4 & 1 & 0.2 & & \\
\hline & TOTAL & & 443 & 100 & & \\
\hline \multirow[t]{8}{*}{$\begin{array}{c}\text { Yaralanma } \\
\text { Bölgeleri }\end{array}$} & Baş bölgesi (1) & $\mathrm{BSS}$ & 109 & 24.6 & & \\
\hline & Yüz bölgesi (2) & FC & 100 & 22.6 & & \\
\hline & Boyun bölgesi (3) & NK & 23 & 5.2 & & \\
\hline & Göğüs bölgesi (4) & TX & 37 & 8.4 & & \\
\hline & Karın bölgesi (5) & AM & 25 & 5.6 & & \\
\hline & $\begin{array}{l}\text { Pelvis Yaralanma- } \\
\qquad \mathrm{sI}(6)\end{array}$ & PS & 25 & 5.6 & & \\
\hline & $\begin{array}{c}\text { Üst extremite } \\
\text { yaralanması (7) }\end{array}$ & UEY & 77 & 17.4 & & \\
\hline & $\begin{array}{c}\text { Alt extremite } \\
\text { yaralanması(8) }\end{array}$ & LEY & 161 & 36.3 & & \\
\hline \multirow[t]{5}{*}{ Klinik Sonuç } & Exitus (1) & & 1 & 0.2 & & \\
\hline & $\begin{array}{l}\text { Sağ|ıklı taburcu } \\
\text { (2) }\end{array}$ & & 405 & 91.4 & & \\
\hline & Servisyatış(3) & & 31 & 7 & & \\
\hline & $\begin{array}{c}\text { Yoğun bakıma- } \\
\text { yatış (4) }\end{array}$ & & 6 & 1.4 & & \\
\hline & TOTAL & & 443 & 100 & 0.537 & $1-4$ \\
\hline
\end{tabular}

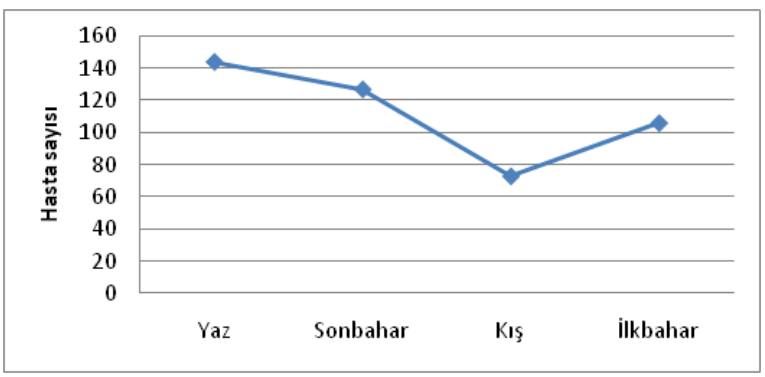

Şekil 1.

Mevsimine göre trafik kazası geçiren hasta sayısı
Hastaların geçirdiği trafik kazası şekillerine re $\% 60,5(n=268)$ ADTK, \%32,3 $(n=143)$ AİTK, $\% 7,2$ $(n=32)$ MK idi. AIS skorunun ortalaması 1.91 \pm 1.28 , ISS skorunun ortalamas1 $3.32 \pm 3.76$ idi. AIS'nin ortanca değeri 2 (1-10), ISS'nin ortanca değeri 2(1-34) idi. Hastaların GKS değerlendirildiğinde; \%99,8 ( $\mathrm{n}=442)$ GKS grup 1, \%0,2 (n=1) GKS grup 3 idi. Hastaların nihai sonuçları değerlendirildiğinde; \%91,4 ( $\mathrm{n}=405)$ sağlık ile taburculuk, \%7 (n=31) servise yatış, \%1,4 $(n=6)$ yoğun bakıma yatış, \%o2 $(n=1)$ exitus idi. Hastaların yaralanma bölgelerinin dağılımı Tablo I'de verilmiştir. Yaralanma bölgeleri ile trafik kazası şekli arasında istatistiksel olarak anlamlı ilişki bulunmadı( $>0.05)$. Fakat yaralanma bölgeleri ile trafik kazası şekilleri arasında ADTK geçiren hastalar, AİTK ve MK geçirenlere göre tümyaralanma bölgelerinde daha fazla idi (Tablo I). Trafik kazası oluş şekline göre ADTK her iki cinsiyette yüksek olması ile birlikte, trafik kazası oluş şeklinin cinsiyetler arası fark istatistiksel olarak anlamlı bulundu $\left(x^{2}: 18.589 ; \mathrm{p}<0.005\right)$ (Tablo II).

Tablo II. Kruskal Wallis-H anatomik travma skorlar1na göre sonuçlar

\begin{tabular}{|llccc|}
\hline \multicolumn{2}{|c|}{ Kruskal-Wallis $\boldsymbol{H}$} & Cor. Coef. & $\boldsymbol{p}$ \\
\hline Trafik kazası oluş şekli & AIS & 5.671 & $0.059^{\mathrm{b}}$ \\
& ISS & 4.897 & $0.86^{\mathrm{b}}$ \\
& Cinsiyet & 18.589 & $0.005^{\mathrm{a}}$ \\
& Yaş grubu & 67.044 & $0.005^{\mathrm{a}}$ \\
Yaş Grubu & & & \\
& AIS & 0.737 & $0.057^{\mathrm{b}}$ \\
& ISS & 0.790 & $0.94^{\mathrm{b}}$ \\
\hline
\end{tabular}

a: Analiz anlamlı 0.05 level $(p<0.05)$; ${ }^{\mathrm{b}}$ : Anlamlı değil. AIS:Kısaltılmış yaralanma ölçeği, ISS:Yaralanma ciddiyet skoru.

Tablo III’te Trafik kazası oluş şekillerinin yaş gruplarına göre dağılımı verilmiştir (Tablo III). 0-2 yaş grup dışındaki tüm yaş gruplarında ADTK yüksek bulundu (Şekil 2). Yaş gruplarının trafik kazası oluş şekline göre istatistiksel olarak anlamlı farklılık bulundu $\left(x^{2}\right.$ : 67.044; $p<0.005$ ) (Tablo II). Trafik kazası oluş şekline travma skorlarından AIS ve ISS arasında istatistiksel olarak anlamlı farkl1lık bulunmadı $\left(\mathrm{x}^{2}: 5.671, \mathrm{p}=0.059\right.$; $\mathrm{x}^{2}$ :4.897, $\mathrm{p}=0.86$ ) (Tablo II). Trafik kazası oluş şekline travma skorlarından GKS arasında FisherExact's testine göre istatistiksel olarak anlamlı farklılık bulunmadi $\left(\mathrm{x}^{2}: 0.654, \mathrm{p}=0.419\right)$. Trafik kazası oluş biçiminin vücut yaralanma bölgelerine göre değerlendirildiğinde ki kare bağımsızlık testine göre gruplar arası yaralanma bölgelerindeki farklılık istatistiksel olarak anlamlı bulunmadı $(\mathrm{p}>0.05)$. Yaş gruplarının yaralanma bölgelerine göre değerlendirildiğinde; sadece pelvis yaralanmasının gruplar arası istatistiksel olarak anlamlı farklılık bulundu ( $22: 8.353, \mathrm{p}=0.039)$. Diğer bölgelerde yaş gruplarına göre istatistiksel olarak anlamlı fark bulunmadı $(\mathrm{p}>0.05)$. Cinsiyet açısından 
AIS ortalaması kadın cinsiyette $1.66 \pm 0.95$, erkek cinsiyette ise 2.05 \pm 1.41 idi. Cinsiyetler aras1 AIS skorunda istatistiksel farklılık açısından değerlendirmek için Mann-Whitney-U testine göre cinsiyetler arası istatistiksel olarak anlamlı farklılık bulundu (z:$2.810, \mathrm{p}<0.05)$. ISS skoru ortalamas1 ise kadin cinsiyet için $2.48 \pm 2.5$, erkek cinsiyet için ise ISS ortalamas1 3.79 \pm 4.20 idi. Cinsiyetler arası ISS travma skoru açısından istatistiksel olarak anlamlı farklılık bulundu (z:-3.335, p<0.05).Yaş gruplarına göre AIS ve ISS skorları değerlendirildiğinde; istatistiksel olarak yaş grupları arasında anlamlı farklılık bulunmadı $\left(x^{2}: 0.737\right.$, $\left.\mathrm{p}>0.05 ; x^{2}: 0.790, \mathrm{p}>0.05\right)$. Trafik kazası oluş biçimine göre AIS ve ISS travma skorları değerlendirildiğinde; istatistiksek olarak anlamlı fark bulunmadi $\left(x^{2}: 4.897\right.$, $\left.\mathrm{p}>0.05 ; x^{2}: 1.824, \mathrm{p}>0.05\right)$.AIS ve ISS travma skorlar1nın hastaların hastaneye yatış ve taburculuk açısından ROC analizi ile değerlendirildiğinde; AIS skorunun kesim noktası 4 (AUC:0.933; min:0.909, max:0.958) üstünde olması, ISS Skorunun ise kesim noktası 7 (AUC:0.975; min:0.961, max:0.988)nin üstünde olmaS1 hastaneye yatış açısından değerlendirilen kesim noktalarıdır (Şekil 3). ISS 7'nin üstünde olanların \%66,1 (n=37) servis yatışları, yoğun bakım yatışlar1 ve ex olmuştur. ISS 7'nin altında olanların ise \% 99.7 ( $\mathrm{n}=386$ ) ise aynı gün taburcu olmuştur. Klinik seyir açısından ISS kesim noktası 7'ye göre 2 gruba ayrılarak klinik seyir açısından değerlendirildiğinde istatistiksel olarak anlamlı farklılık bulundu ( $x 2: 270.255, \mathrm{p}<0.05)$.

Tablo III. Yaş Gruplarına göre trafik kazası oluş şeklinin dağılımı

\begin{tabular}{|llll|}
\hline Yaş Grupları & \multicolumn{1}{c}{ ADTK } & \multicolumn{1}{c}{ AiTK } & MK \\
\hline 0-2 yaş & $\% 46.4(n=13)$ & $\% 50(n=14)$ & $\% 3.6(n=1)$ \\
3-6 yaş & $\% 75.6(n=93)$ & $\% 39.7(n=29)$ & $\% 8.9(n=1)$ \\
7-12 yaş & $\% 99.2(n=107)$ & $\% 52.9(n=54)$ & $\% 11.8(n=3)$ \\
13-17 yaş & $\% 77.4(n=55)$ & $\% 41.3(n=46)$ & $\% 9.2(n=27)$ \\
\hline ADTK: Araç diş1 trafik kazas1, AITK: Araç içi trafik \\
kazas1, MK: Motorsiklet kazas1
\end{tabular}

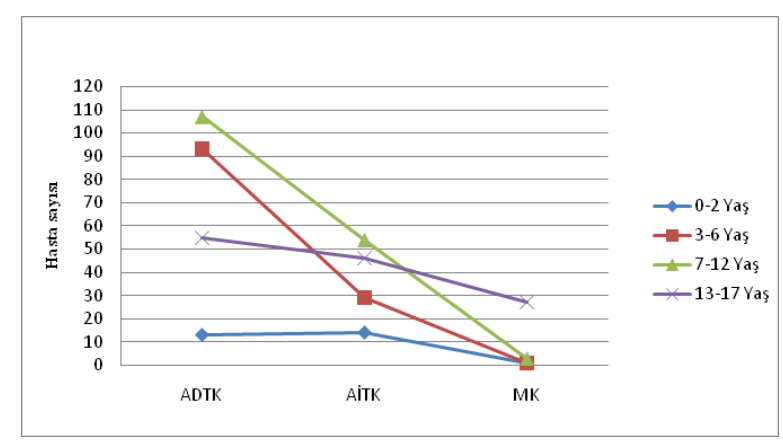

(ADTK: Araç dışı trafik kazası, AITK: Araç içi trafik kazası, MK: Motorsiklet kazası)

Şekil 2.

Yaş gruplarının trafik kazası mekanizmasına göre dă̆llımı

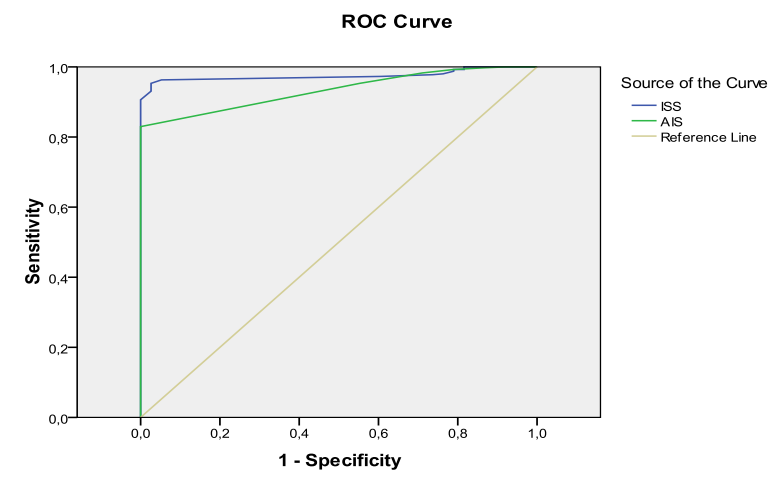

Sekil 3 .

AIS ve ISS travma skorlart; ROC analizine göre, AIS 4'ün üstü (AUC: 0.933; min: 0.909, max: 0.958) ve ISS 7'nin üstü (AUC: 0.975; min: 0.961, max: 0.988) hastaneye yatış açısından değerlendirilen kesim noktalarıdır.

\section{Tartışma}

Trafik kazaları çocukluk çağı ölüm sebeplerinin başında gelmektedir ${ }^{16}$. 2018 yılında trafik kazalarına bağlı olarak; 55611 çocuk yaralanması olmuş, 665 çocuk ise hayatını kaybetmiştir². Özellikle 1-14 yaş arası ölümlerin başlıca nedenlerinden travma gelmektedir ${ }^{17}$. Yaşamın erken dönemlerinde ve yürüme çağında ev içindeki düşmeler en sık travma nedeni iken yaş ilerledikçe trafik kazaları daha yaygın görülmeye başlamaktadır. Yapılan bir çalışmada bizim çalışmamızla benzer şekilde cinsiyetler arasında erkek çocuklarda trafik kazası geçirme oranı kızlardan daha fazla bulunmuştur ${ }^{7}$. Yapılan bazı çalışmalarda bizim çalışmamızla benzer şekilde cinsiyet olarak erkek cinsiyetin fazla olduğu bulunmuş bu durumunda erkek çocukların daha fazla özgür ve tehlike arz eden oyunları tercih ettikleri düşünülmüştür ${ }^{18-21}$.

Çocuk hastaların vücut kitle endeksi ve vücut alanları küçük olduğundan dolayı travmalarda tüm vücut etkilenmektedir. Çocuk travmaları ile ilgili yapılan bazı çalışmalara göre en sık iskelet sistemi yaralanması bildirmişlerdir ${ }^{22,23}$. Bizim çalışmamızda da en sık üst ve alt ekstremite yaralanmaları olup, bu çalışmalar ile paralellik göstermektedir. Çocuk Travmaları ile yapılan çalışmalar da bizim çalışmamızdan farklı olarak baş bölgesi yaralanması daha fazla görülmüştür ${ }^{24,25}$. $\mathrm{Bu}$ durum bize yapılan travma çalışmalarının bizim çalışmadan farklı olarak travma mekanizmaları farklı olduğunu düşündürmüştür.

Yapılan bazı çalışmalarda gerçekleşen trafik kazaları en fazla yaz, en az ise kış mevsiminde görülmüştür ${ }^{26,27}$. Başka bir çalışmada kuzey yarım kürede yaz aylarında çocuk travmaların fazla olduğu bildirilmiştir ${ }^{28,29}$. Bizim çalışmamızda da benzer sonuçlar çıkmış olup, mevsimsel olarak günlerin uzaması ve insanların ev 


\section{Pediatrik Hastalarda Travma Skorları}

dışında fazla zaman geçirmesinden kaynaklandığı düşünülmüştür.

Travmalı çocukların morbitide ve mortalite oranlarının azaltılması amacıyla üretilmiş çeşitli travma skorlama sistemleri vardır ${ }^{30,31}$. Bu skorlardan birkaçı ISS (Yaralanma ciddiyet skoru), AIS (Kısaltılmış yaralanma ölçeği) ve Glaskow koma skalasıdır ${ }^{32}$. Skorlama sistemlerinin her birinin kendine özgü sınırları vardır. ISS ve AIS skorları anatomik bölgeleri değerlendirirken fizyolojik değişkenler değerlendirilemez. Aynı şekilde GKS içinde fizyolojik değişkenler değerlendirilememektedir. Allen ve ark. travmalarla ilgili yaptığ bir çalışmada Travma skorları değerlendirildiğinde ISS ve GKS skorlarında fizyolojik değerlendirme yapılamasa da mortalite öngörmede bağımsız belirleyici olarak bildirmişlerdir ${ }^{31}$. Çalışmamızda Trafik kazası oluş şekline göre skorlama sistemlerinin puanlamalarında değişiklik bulunmadı. Bu durum bize trafik kazalarında ilk bakıdan itibaren hastanın ciddiyetinde kaza mekanizmalarını geri planda bırakılabileceğini düşündürmüştür. Algnham ve ark.pediatrik travma hastalarında yaptığı çalışmada ISS skoru uzamış hastane yatışlarında ortalaması 15.4 olup, kısa süreli hastane yatışlarında ise ISS 6.8 bulunmuştur $^{33}$. Çalışmamız yapılan bu çalışmadan dizaynı farklı olmasıyla birlikte ISS 7'nin üstünde olması hastaneye yatış için kesim noktasıdır. Çalışmamız Algnham ve ark çalışması ile hastaneye yatış açısından paralellik göstermektedir.

\section{Sonuç}

Çalışmamızda kullanılan AIS ve ISS skorlarının yaygın kullanımının, yanında fizyolojik belirteçleri göstermemesinin de dezavantajları olmakla birlikte kaza sahasında travma merkezlerinin derecelerine göre transfer planlamasında hastanın zaman kaybetmemesi adına kullanılabilecek skorlar olduğunu düşünmekteyiz.

\section{Kaynaklar}

1. Polat O. Adli travmatolojide trafik kazalarına bakış. Adli Tıp Bülteni; 1996;1:18-25.

2. TÜİK.(2018).Number of accidents, persons killed and injured by year, http://www.tuik.gov.tr/ (Access date: 26.03.2018).

3. Kidder K, Stein J, Frase J. The health of Canada's children. A $\mathrm{CICH}$ profile 3rd ed. Ottawa (Ontario): Canadian Inst of Child Health, 2000:81-102.

4. DiGuiseppi C, Roberts IG. Individual-level injury prevention strategies in the clinical setting. Future Child 2000; 10:53-82.

5. Brook U, Boaz M. Children hospitalized for accidental injuries: Israeli experiences. Patient Education and Counseling 2003; 51: 177-82.

6. Pitone ML, Attia MW. Patterns of injury associated with routine childhood falls. Pediatr Emerg Care 2006;22:470-4.
7. Akay MA, Gürbüz N, Yayla D, Levent Elemen L, Yıldız Ekingen GY, Esen H, Yıldız T, İlçe Z. Acil servise başvuran pediatrik travma olgularının değerlendirilmesi. Kocaeli Tıp Dergisi 2013; 3: 1-5.

8. Şengül AT, Kutlu T, Büyükkarabacak YB, Yetim TD, Bekdemir OS, Cemgil Öztürk C, Başoğlu A.Effects of trauma scores on prognosis in chest traumas. Türk Göğüs Kalp Damar Cerrahisi Dergisi 2012;20(4):805-811.

9. MacKenzie EJ. Injury severity scales: overview and directions for future research. Am J Emerg Med 1984;2:537-48.

10. Husum H, Strada G. Injury Severity Score versus New Injury Severity Score for penetrating injuries. Prehosp Disaster Med 2002;17:27-32.

11. Champion HR, Copes WS, Sacco WJ, Lawnick MM, Keast SL, Bain LW Jr, et al. The Major Trauma Outcome Study: establishing national norms for trauma care. J Trauma 1990;30:1356-65

12. Chan B, Guadry P, Gratton-Smith TM, McNeil R. The Use of Glasgow Coma Scale in Poisoning. J Emerg Med, 1993; 11: 579-82.

13. Lefering R. Trauma score systems for quality assessment.Eur $\mathrm{J}$ Trauma 2002;28:52-63.

14. Kalaycioglu N, Kaplan ME, Unsel M. Prognostic Factors and Scoring Systems in ICU. YoğunBakımDergisi 2006;6(3):147159.

15. Stevenson,M Segui-Gomez M, Lescohier I, Scala CD, McDonald-Smith G.An overview of the injury severity score and the new injury severity score Injury Prevention .2001;7:10-13

16. Sala D, Fernandez E, Morant A, Gasco J, Barrios C. Epidemiologic aspects of pediatric multiple trauma in a Spanish urban population. J Pediatr Surg. 2000;35:1478-81.

17. Pant, P. R., Towner, E., Pilkington, P., Ellis, M., \& Manandhar, D. Community perceptions of unintentional child injuries in Makwanpur district of Nepal: A qualitative study. BMC Public Health.2014:14(1), 476.

18. Mutto, M., Lawoko, S., Nansamba, C., Ovuga, E., \& Svanstrom, L. Unintentional childhood injury patterns, odds, and outcomes in Kampala City: An analysis of surveillance data from the National Pediatric Emergency Unit. $J$ Inj Violence Res.2011: 3(1); 13-18.

19. Zia, N., Khan, U. R., Razzak, J. A., Puvanachandra, P., \& Hyder, A. A. Understanding unintentional childhood home injuries: Pilot surveillance data from Karachi, Pakistan. BMC Res Notes.2012: 5; 37.

20. Isaac, K. N., Van Niekerk, A., \& Van As, A. B. Child road traffic crash injuries at the Red Cross War Memorial Children's Hospital in Cape Town, South Africa in 1992, 2002 and 2012. Int J Inj Contr Saf Promot. 2014:1-7.

21. Esteban E, Bujaldon E,Mireıa Esparza, Jordan I, Esteban ME.Sex differences in children with severe health conditions: Causes of admission and mortality in a Pediatric Intensive Care Unit. American Journal of Human Biology.2015;27:613-9.

22. Yazıcı S, Can M.Disability Due to Traffic Accidents in Children and Affecting Factors. Adli Tıp Bülteni, 2019; 24(1): 5156.

23. Jalalvandi F, Arasteh P, Faramani RS, Esmaeilivand M.Epidemiology of Pediatric Trauma and Its Patterns in Western Iran: A Hospital Based Experience. Global Journal of Health Science; 2016: 8( 6); 139-146.

24. Sozuer E.M, İkizceli İ,Avşaroglu L, Yurumez Y,Yavuz Y,Yücel M.Trauma Characteristics of Primary-school-age Children in the Emergency Department.2004;4(2):59-63.

25. Aoki M, Abe T, Saitoh D, Oshima K. Epidemiology, Patterns of treatment, and Mortality of Pediatric Trauma Patients in Japan. Scientıfic Reports. 2019 9:917;1-7. 


\section{Atik, ark.}

26. Karayolu Trafik Kaza İstatistikleri, 2013. Emniyet Genel Müdürlüğü ve Türkiye İstatistik Kurumu, Türkiye İstatistik Kurumu Matbaası, Ankara, 2014.

27. Embleton DB,Ertoran I,Onen N,Ozkan A,Mersin H,Tekeli MC Mortality And Morbidity in Children As Traffic Accident Victims. Kocatepe Medical Journal 2016; 17:84-88.

28. Wareham K., Johansen A., Stone M. D., Saunders J.,Jones S., Lyons R. A. Seasonal variation in the incidence of wrist and forearm fractures, and its consequences. Injury.2003;34:21922.

29. Tarğal AS, Haberal B, Hakan Şeşen H, Demirkale I,Ateş A, Altay M The Etiology And Epidemiology Of Fractures In Children Presenting To The Emergency Room In One Year: Study With 1878 Patients. Akademik Araştırma Tıp Dergisi . 2017; 2(2): 44-48.
30. Potoka DA, Schall LC, Ford HR. Development of a novel agespecific pediatric trauma score. J Pediatr Surg.2001; 31: 10612.

31. Allen CJ, Wagenaar AE,Horkan DB,Baldor DJ, Hannay WM,Tashiro J, Namias N, Sola EJ. Predictors of mortality in pediatric trauma: experiences of a level 1 trauma center and an assessment of the International Classification Injury Severity Score (ICISS). Pediatr Surg Int .2016; 32:657-663.

32. Kanmaz T, Çakmak M, Barlas M, Dindar H, Mecdel Y, Özgüner İF ve ark. Pediatrik travma skorlaması. Pediatrik Cerrahi Dergisi 1995; 9: 330-2.

33. Alghnam S, Towhari JA, Babtain IA, Nahdi MA, Aldebasi MH , Alyami M, Alkhalaf H. The associations between injury mechanism and extended hospital stay among pediatric patients: findings from a trauma Center in Saudi Arabia. BMC Pediatrics .2019; 19(177):2-8. 